\title{
PATRIMONIO FOTOGRÁFICO DE CATALUNYA EN LA RED
}

\section{Laia Foix}

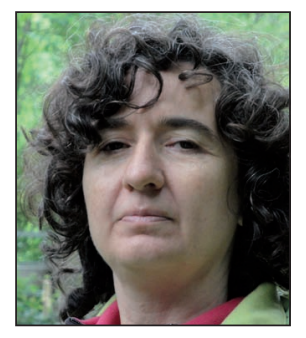

Laia Foix es coordinadora del área de documentación del Institut d'Estudis Fotogràfics de Catalunya. Es diplomada en biblioteconomía y documentación por la Facultat de Biblioteconomia $i$ Documentació de la Universitat de Barcelona, donde imparte docencia sobre gestión de fondos fotográficos. Autora de diversos artículos sobre la gestión de la fotografía en entidades culturales.

Institut d'Estudis Fotogràfics de Catalunya Compte d'Urgell, 187. 08036 Barcelona Ifoix@iefc.cat

\section{Resumen}

Se analiza el patrimonio fotográfico de Catalunya y se describen los problemas para cuantificarlo. Se valora su presencia en internet a partir de 26 entidades catalanas que gestionan archivos fotográficos y que tienen fotografías consultables en la Red o proyectos de digitalización iniciados y un mínimo de 5.000 imágenes ya digitalizadas. De estas 26, 15 ofrecen acceso online a un total de más de 250.000 fotografías. De las entidades incluidas en el estudio se detalla el volumen total del fondo, la parte digitalizada y cuántas imágenes están en la Red. La diferencia entre imágenes digitalizadas e imágenes accesibles por internet se explica por las dificultades en afrontar la catalogación y la publicación con software adecuado, y la gestión de los derechos legales inherentes a las fotografías.

\section{Palabras clave}

Patrimonio fotográfico, Catalunya, Difusión en internet, Online, Digitalización, Colecciones, Archivos fotográficos, Problemas, Evolución.

\section{Title: Photographic heritage of Catalonia on the Net}

\begin{abstract}
The photographic heritage of Catalonia is analysed, first specifying which photographs to include in this study and then describing the problems of quantifying this heritage. The online presence of this photographic heritage is assessed on the basis of the 26 Catalan institutions that manage photography archives and either make photographs available on the network or have started digitization projects that now include at least 5,000 digitized images. Of these 26 entities, 15 offer Internet access to their collection of photographs, with a total of more than 250,000 photographs available.

The study details the total size of each collection, number of digitized images, and how many of these images are available online. The difference between digitized images and images available online is explained by the difficulties encountered in digitizing, cataloguing, and publishing the images online with the appropriate software and managing copyright issues related to the photographs.
\end{abstract}

\section{Keywords}

Photographic heritage, Catalonia, Internet dissemination, Digitization projects, Photographic archives, Problems, Online.

Foix, Laia. "Patrimonio fotográfico de Catalunya en la Red". El profesional de la información, 2011, julio-agosto, v. 20, n. 4, pp. 378-383. http://dx.doi.org/10.3145/epi.2011.jul.03

\section{Introducción}

Para la elaboración de este estudio se ha realizado una primera búsqueda bibliográfica sobre el patrimonio fotográfico en Catalunya. Se ha constatado la inexistencia de bibliografía sobre el patrimonio accesible en internet, por lo que se ha iniciado una investigación en dos líneas. La primera, a partir de la exploración de la Red en general y de los espacios virtuales de las entidades gestoras de archivos fotográficos en particular. La segunda, interrogando directamente a las entidades con archivos fotográficos especialmente cuantiosos, así como a aquellas que nos constaba que estaban trabajando en proyectos de digitalización de sus fondos fotográficos y/o proyectos de difusión de estos fondos en la Red. 
Se ha contactado con 26 entidades que gestionan archivos fotográficos y que tienen fotografías accesibles en la Red o han puesto en marcha proyectos de digitalización que suponen un mínimo de 5.000 imágenes ya digitalizadas. La recogida de datos se realizó entre los meses de enero y marzo de 2011.

\section{El estudio incluye todos los archivos fo- tográficos patrimoniales de Catalunya que ofrecen la consulta de sus fondos en la Red}

El estudio incluye todos los archivos fotográficos patrimoniales de Catalunya que ofrecen la consulta de sus fondos en la Red. Además se tuvieron en cuenta otros archivos que han iniciado procesos de digitalización, aunque algunos todavía no tengan sus fondos online. Son archivos que custodian el patrimonio fotográfico a los que acuden investigadores, historiadores, editores de contenidos, y cualquier persona interesada en aproximarse a nuestro pasado a través de la imagen fotográfica.

La inclusión de otros fondos con una riqueza patrimonial indiscutible y que han iniciado procesos de digitalización que aún no son visibles, no es exhaustiva. Supondría por sí solo un estudio aparte. Sirvan los centros incluidos en este trabajo como muestra del patrimonio fotográfico existente que en un futuro próximo aumentará su visibilidad de forma importante.

\section{Consideración de patrimonio fotográfico en este estudio}

En cuanto a su ubicación, nos ceñimos a fotografías custodiadas en archivos organizados, es decir, aquellos que tienen por objetivos principales la conservación y difusión de sus fondos para conocimiento y uso de la ciudadanía. Entendemos el concepto de archivo en su sentido más amplio y teniendo presente que las colecciones muchas veces se encuentran en otro tipo de entidades documentales, como bibliotecas o museos; o incluso en entidades culturales o académicas que han valorado positivamente esta documentación fotográfica y han creado y gestionado archivos fotográficos propios (como por ejemplo, el Centre Excursionista

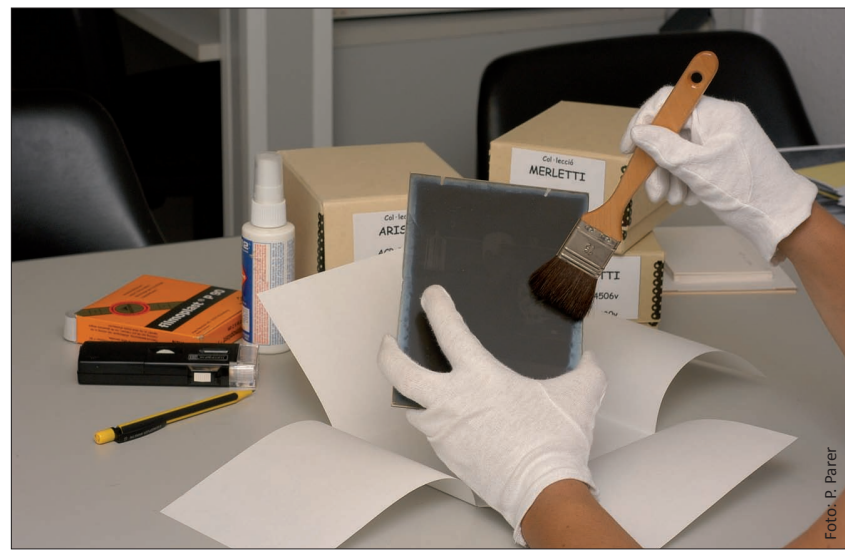

Limpieza de cliché en soporte de vidrio

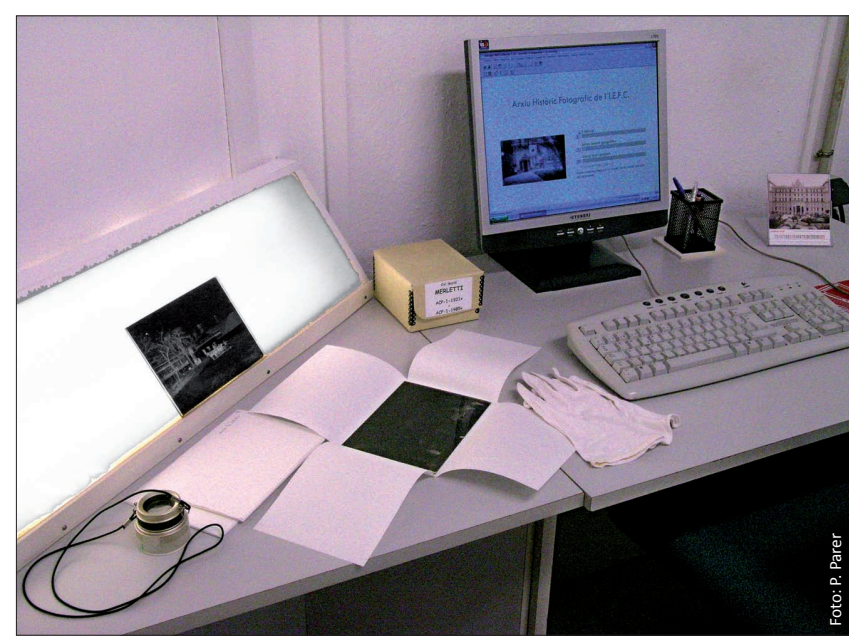

Tratamiento documental en el Institut d'Estudis Fotogràfics de Catalunya

de Catalunya, el Institut del Teatre, o el Institut d'Estudis Fotogràfics de Catalunya, por citar sólo algunos).

En cuanto a su valor patrimonial, nos referimos a documentos fotográficos considerados por sí mismos como patrimonio, más allá de la imagen que reproducen. Fotografías que por su antigüedad, autoría, o por su constitución formal, tienen un valor intrínseco e inseparable del objeto físico que las configura. Pueden reproducir asimismo objetos del patrimonio cultural (monumentos, obras de arte) o incluso del patrimonio cultural inmaterial (danzas, tradiciones, etc.), pero el valor de su contenido no desmerece su valor como objetos fotográficos.

Quedan fuera del ámbito de este estudio las imágenes fotográficas que reproducen objetos del patrimonio cultural y que se han obtenido contemporáneamente con el objetivo de describir, ilustrar y difundir los objetos que muestran.

Así, no se han tomado en consideración por ejemplo las imágenes contenidas en el buscador Museus en línea ${ }^{1}$, que son fotografías contemporáneas de objetos no fotográficos custodiados por los museos de Catalunya que han participado en este proyecto y que actualmente -febrero 2011- reúne más de 250.000 objetos con sus correspondientes reproducciones fotográficas. En un futuro suponemos que también se incluirá en este buscador el patrimonio fotográfico custodiado por estos museos, algunos de ellos con archivos fotográficos de gran relevancia (como el Museu Marítim de Barcelona), pero actualmente no es posible que las entidades participantes puedan introducir y gestionar sus datos referentes a patrimonio fotográfico en el buscador, que incluye funciones de gestor documental.

Tampoco se ha tenido en cuenta el buscador Calaix ${ }^{2}$, del Departament de Cultura i Mitjans de Comunicació (DCMC) de la Generalitat de Catalunya que, a la espera de comprobar las fotografías que incluirá, deducimos que serán también imágenes obtenidas en la actualidad para ilustrar el patrimonio cultural que recopila este recurso en línea, según se explica en su web.

También se ha excluido por la misma razón el buscador CliCat Cultura de la Direcció General del Patrimoni Cultural de la Generalitat de Catalunya, que recoge, entre otra documentación multimedia, fotografías obtenidas contemporáneamente del patrimonio cultural de Catalunya. 


\section{Volumen}

El punto de partida para cualquier estudio en este campo es conocer el volumen de fotografías en los fondos fotográficos patrimoniales de Catalunya y en qué entidades se encuentran. La cuantificación del patrimonio permite contextualizar la cantidad de imágenes disponibles en la Red. La obtención de estos datos a día de hoy es sin embargo imposible a partir de la bibliografía existente.

Si bien en las Jornades Catalanes de Fotografia, celebradas en Barcelona en 1980, ya se comentaba la necesidad de contar con un libro blanco de la fotografía en Catalunya que permitiera conocer el alcance y la situación real del patrimonio fotográfico, no hay datos concretos hasta diez años después. El primer documento elaborado con esta voluntad es la ponencia de Carles Vicente-Guitart (1990). El autor envió un cuestionario a 228 centros públicos y privados de Catalunya de los cuales 128 , con fondos de imágenes, lo completaron. Aun así, las carencias y la parcialidad de los datos recogidos evidenciaba la necesidad de realizar un censo-inventario de fondos de imágenes fijas. Un instrumento que ya entonces era "tan imprescindible como inexistente", según el mismo autor.

La presencia de patrimonio fotográfico de Catalunya en la Red es todavía muy pobre

En 1996 se publica el Llibre blanc del patrimoni fotogràfic a Catalunya, coordinado por Cristina Zelich (1996), entre cuyos objetivos incluía poder establecer el alcance del patrimonio fotográfico. Se envió un cuestionario a 232 entidades, de las que respondieron 106, y sólo se tuvieron en cuenta 92 en el análisis final. Estas 92 entidades sumaban 10.000.000 de fotografías. Es evidente que los datos obtenidos no eran representativos de la totalidad del patrimonio fotográfico existente entonces y custodiado en entidades gestoras.

Dos años después se publica en internet el Inventari d'arxius fotogràfics públics i privats de Catalunya, coordinado por Blanch (1998). Aun siendo una iniciativa privada, es la que incluye una muestra más amplia, publicando datos correspondientes a 168 centros. Aquí aumentaría el patrimonio hasta los 14.500 .000 de fotografías aproximadamente.

Por último el DCMC emite cada dos años la Estadística d'Arxius (2007), restringida a las entidades archivísticas - de titularidad pública o privada- pero de interés para este estudio ya que contempla la cuantificación de los fondos fotográficos. En este caso, con fecha de 2004 consta un total de 14.535.177 fotografías. Esta cantidad implica un aumento del número total respecto a los inventarios anteriores, ya que muchas de las entidades contempladas en el Inventari d'arxius fotogràfics públics i privats de Catalunya no están en la Estadística d'Arxius, y viceversa. Podemos intuir que la suma real es muy superior.

Así pues, a pesar de la importante labor realizada en los fondos fotográficos, todavía no existe un inventario exhaustivo del patrimonio fotográfico. Lo que sí podemos avanzar es que las 26 entidades contempladas en este estudio suman ya más de 15.774 .000 imágenes.

\section{Presencia en la Red}

En los últimos años muchos archivos han iniciado proyectos de digitalización y de publicación de sus fondos en la Red, para potenciar la difusión del patrimonio y dar acceso a sus imágenes. Pero la presencia de patrimonio fotográfico de Catalunya en la Red es todavía muy pobre. En este artículo hemos querido realizar un estudio de campo que nos dé cantidades contrastadas de esta presencia, para visibilizar el trabajo realizado y poder reflexionar sobre las posibles causas de la lentitud de este proceso. No es objeto de este estudio analizar los criterios de digitalización de las diferentes entidades, muy diversos en su intencionalidad y en su causalidad, como es previsible teniendo en cuenta la diversidad institucional de estos archivos.

Actualmente hay en la Red poco más de 268.000 imágenes accesibles del patrimonio fotográfico de Catalunya, que corresponden a una parte de los fondos y colecciones de 15 entidades (gráfico 1). Éstas utilizan diferentes vías para la difusión en internet: buscadores, sus propias webs, o en algunos casos ambas opciones.

El buscador Arxius en línia ${ }^{3}$ de la Generalitat difunde documentación de su red de archivos, que tienen parte de sus fondos digitalizados: más de 150.400 fotografías. Incluye el Arxiu Nacional de Catalunya, que también difunde estas imágenes desde su propia web, y otros 6 archivos de la red institucional (archivos comarcales y provinciales): Arxiu Històric de Tarragona, Arxiu Comarcal del Pallars Sobirà, Arxiu Històric de Girona, Arxiu Comarcal de la Cerdanya, Arxiu Comarcal de l'Alt Empordà y Arxiu Comarcal de l'Alt Penedès.

El buscador Eureca ${ }^{4}$ da acceso a más de 74.000 fotografías que pertenecen a cuatro entidades. Dos de ellas (la Unitat Gràfica de la Biblioteca de Catalunya y el Institut Cartogràfic

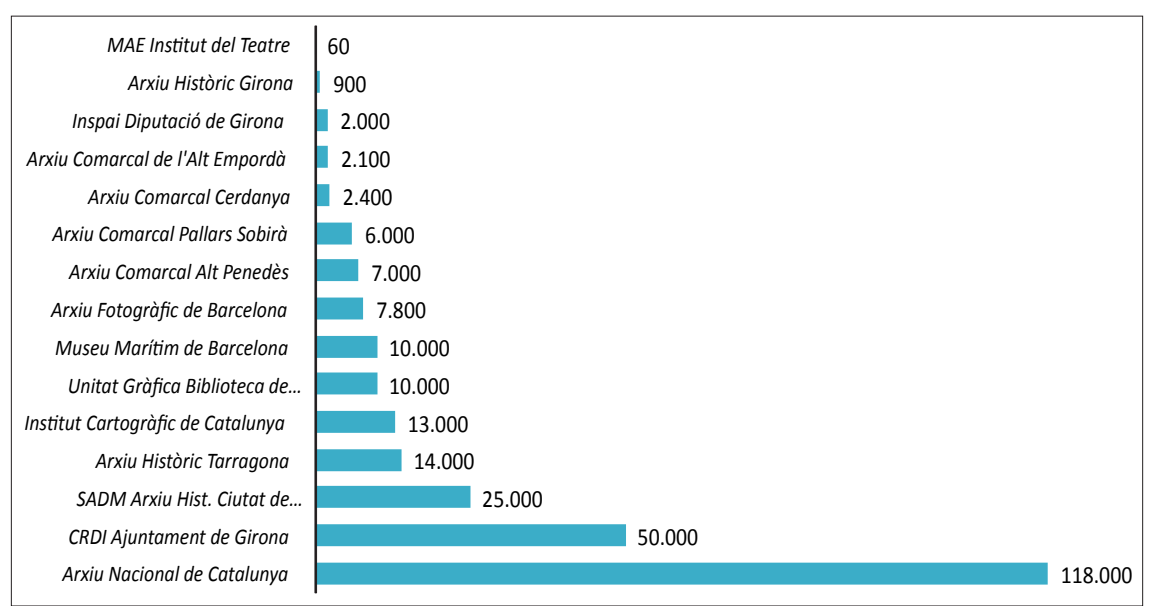

Gráfico 1. Fotografías en la Red 
de Catalunya) lo hacen desde el fondo que tienen hospedado en la Memòria Digital de Catalunya, recurso que está incluido en Eureca. También se encuentran las 13.000 imágenes del Institut Cartogràfic de Catalunya no incluidas en la Memòria Digital de Catalunya, y 50.000 imágenes del CRDI de l'Ajuntament de Girona, ambos fondos accesibles también desde la web de las propias entidades. Eureca también contiene el fondo del Museu de les Arts Escèniques de I'Institut del Teatre que, si bien actualmente sólo incluye una cantidad simbólica de su archivo fotográfico -apenas un centenar de fotografías- esto cambiará en los próximos meses. Este fondo también se puede consultar en la web de la propia entidad.

Finalmente hay cuatro entidades con fondos digitalizados consultables en internet desde sus propias webs, y que no se encuentran en buscadores. Son el Museu Marítim de Barcelona, que tiene 10.000 fotografías; el Inspai de la Diputación de Girona, que tiene 2.000; el SADM de l'Arxiu Històric de la Ciutat de Tarragona, que el pasado mes de marzo dio acceso desde su web a 25.000; y el Arxiu Fotogràfic de Barcelona, con más de 7.800 fotografías.

Cerca del $83 \%$ del patrimonio fotográfico de Catalunya accesible online, lo está desde los buscadores citados. Sorprende sin embargo que Arxius en línia no esté incluido en Eureca, ya que ambos han surgido del DCMC. Un $17 \%$ aproximadamente del patrimonio fotográfico en la Red es accesible sólo desde las propias entidades, con la disminución que esto implica en su difusión y localización.

\section{Sorprende que Arxius en línia no esté in- cluido en Eureca}

\section{El futuro que llega: fondos ya digitalizados}

Apenas un $1,7 \%$ del patrimonio fotográfico custodiado por las entidades incluidas en este estudio está digitalizado y presente en la Red (unas 268.000 fotografías). Pero si nos fijamos en cuánto está ya digitalizado, la cantidad asciende a más de 1.471 .000 imágenes, cerca de un 9,3\% (gráfico 2 ).
¿Por qué esta diferencia? Los procesos de digitalización surgen muchas veces de la iniciativa particular, dentro de entidades que no dependen orgánicamente de redes institucionales, o no encuentran en estas redes la infraestructura donde incluir los procesos de digitalización y difusión iniciados.

Estas dificultades no les han impedido trabajar con vistas a un futuro que ya es presente: facilitar el acceso a la fotografía no sólo mediante su descripción catalográfica sino también incluyendo la imagen, y la perspectiva de ampliar la difusión con la publicación en la Red.

En 2011 está previsto que muchas de estas imágenes estén presentes en la Red; quizá ya sea realidad en el momento en que este artículo sea publicado. EI CRDI de l'Ajuntament de Girona tiene previsto incrementar en 150.000 fotografías su fondo en internet. El Arxiu Comarcal de l'Alt Empordà, en más de 7.000, y el Arxiu Comarcal del Pallars Sobirà, en más de 4.000, ambas entidades haciéndolas visibles a través del buscador Arxius en línia. El Museu d'Arts Escèniques de l'Institut del Teatre hará accesibles más de 40.000. Otras entidades que ahora no son visibles en internet, cambiarán esta situación: el Arxiu Fotogràfic d'Olot tiene previsto poner 40.000 fotografías en la Red; y el Centre Excursionista de Catalunya, como fruto de un importante proyecto que está llevando a cabo en toda su área de documentación, publicará también una cantidad destacada.

En pocos meses el patrimonio fotográfico de Catalunya en la Red se verá más que duplicado. La mayor parte accesible desde los buscadores citados, lo cual facilita su visibilidad y la consulta por parte de los usuarios.

\section{Dificultades para la visibilidad de este patrimonio en la Red}

La digitalización propiamente dicha es seguramente la parte más fácil, económica y factible para cualquier entidad. Sin embargo la preservación digital es una asignatura pendiente para muchos archivos con colecciones digitales importantes. Así mismo, acceder a infraestructuras adecuadas y estar continuamente informado en lo que respecta a directrices y recomendaciones en esta materia es difícil para unos profesionales que ya ven su día a día marcado por una multidisciplinariedad a veces agotadora en entidades donde las plantillas son muchas veces unipersonales.

La catalogación de las imágenes es un obstáculo mayor al requerir más recursos por ser una tarea más laboriosa. La desintermediación propia de la consulta en internet, dificulta la recuperación de las imágenes si no se revisa la catalogación existente, teniendo presentes las características de esta consulta autónoma por parte de usuarios de perfiles muy diversos.

En cuanto a la difusión, disponer de un software que permita la publicación en la Red, con todo lo que implica esta in- 


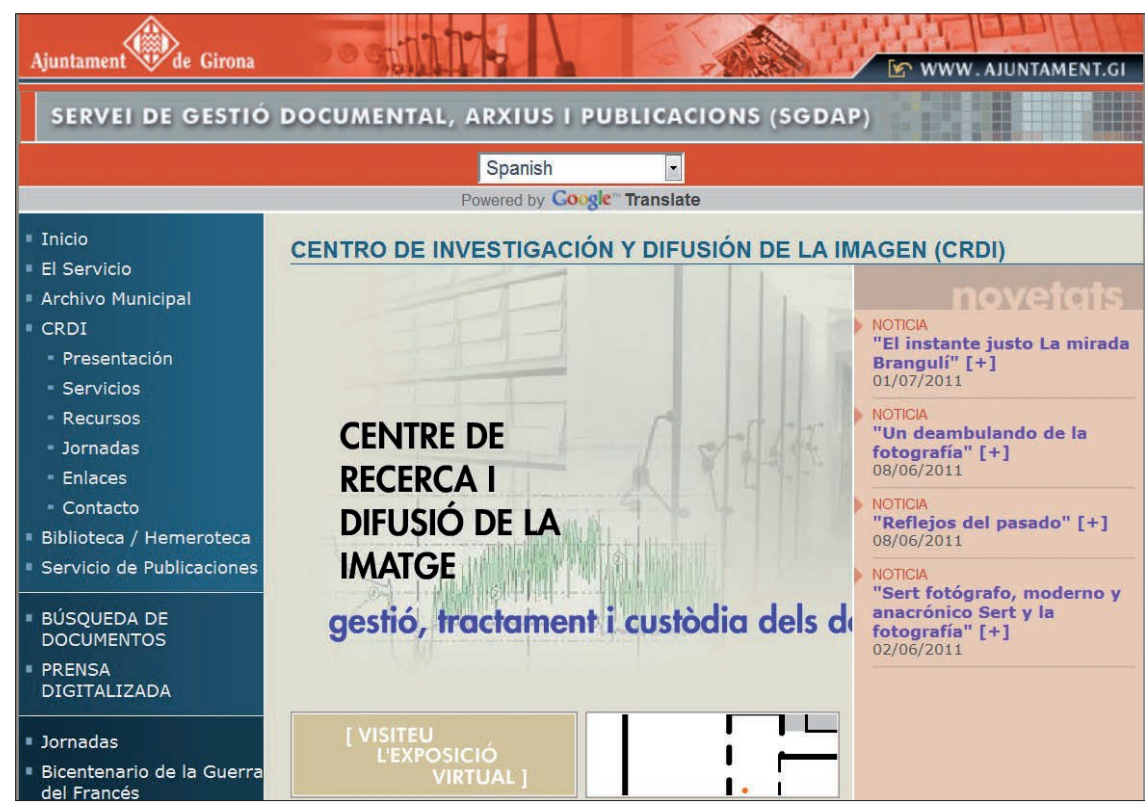

Con 4 millones (mayo 2011), el Centre de Recerca i Difusió de la Imatge (CRDI) del Ajuntament de Girona es la entidad catalana con mayor número de fotografías.

http://www.girona.cat/sgdap

\section{La preservación digital es una asignatura} pendiente para muchos archivos con colecciones digitales importantes

fraestructura (servidores, depósitos digitales, etc.), está muchas veces fuera del alcance de algunas entidades. Incluir el fondo en plataformas colaborativas o cooperativas, buscadores o redes, tiene ventajas pero también dificultades propias de una tradición muy pobre en el uso de estándares. La diversidad de entidades que custodian fondos fotográficos implica también diferentes tradiciones documentales (museística, archivística, biblioteconómica) con los diferentes modelos descriptivos que les son propios. Esta falta de estandarización ha estado presente hasta hace muy poco también en la mayor parte del software comercializado, lo que añade dificultades para la migración de datos a otros sistemas, como pueden ser las redes o los buscadores.

Por último, la aplicación de la legislación inherente a las fotografías es a veces una dificultad añadida para su difusión. La gestión de los derechos de autor, y concretamente la de los derechos de explotación, es difícil en muchos fondos y colecciones formados hace años. En épocas en que la palabra dada tenía un valor equivalente a los documentos firmados, el desconocimiento o la ingenuidad de los profesionales perpetuó la custodia de fondos en un limbo legal que hoy dificulta o imposibilita su difusión. Otra legislación, como la referente a la protección de la imagen y la intimidad, o protección de datos personales, también ha supuesto una barrera para muchos archivos fotográficos cuando se han propuesto difundir las imágenes.

El trabajo hecho hasta el momento se debe al convencimiento del valor del patrimonio fotográfico que entre todos custodiamos y a la voluntad de preservarlo y de difundirlo, a pesar de las carencias de muchos archivos fotográficos. Trabajar coordinadamente con el apoyo y el asesoramiento de presencia en la Red las entidades responsables de la gestión del patrimonio permitiría mejorar y avanzar en este proyecto común que es la difusión en la Red para beneficio de la ciudadanía.

\section{Agradecimientos}

Este artículo no hubiera sido posible sin la colaboración de los profesionales de las distintas entidades citadas que han facilitado datos actualizados de sus fondos y del estado de los procesos de digitalización:

Elisenda Ardèvol (Institut Cartogràfic de Catalunya), Ramon Barnadas (Centre Excursionista de Catalunya), Anna Bonfill (Arxiu d'Imatges d'Olot), M. Antònia Carrasco (SPAL, Diputació de Barcelona), Carme Carreño (Institut

\begin{tabular}{|c|c|c|c|}
\hline Entidad & $\begin{array}{l}\text { Fotogra- } \\
\text { fías }\end{array}$ & $\begin{array}{c}\text { Fotografías } \\
\text { digitalizadas }\end{array}$ & $\begin{array}{c}\text { Fotografías } \\
\text { en la Red }\end{array}$ \\
\hline CRDI Ajuntament de Girona & 4.000 .000 & 50.000 & 50.000 \\
\hline Arxiu Nacional de Catalunya & 2.000 .000 & 125.000 & 118.000 \\
\hline Arxiu Fotogràfic de Barcelona & 2.000 .000 & 25.000 & 7.800 \\
\hline Inspai Diputació de Girona & 1.000 .000 & 12.000 & 2.000 \\
\hline Institut d'Estudis Ilerdencs & 800.000 & 200.000 & 0 \\
\hline Arxiu Històric Fotogràfic IEFC & 800.000 & 40.000 & 0 \\
\hline $\begin{array}{l}\text { SADM Arxiu Històric de } \\
\text { Tarragona }\end{array}$ & 750.000 & 25.000 & 25.000 \\
\hline Arxiu Històric de Badalona & 730.000 & 25.000 & 0 \\
\hline Arxiu Històric de Sabadell & 500.000 & 100.000 & 0 \\
\hline Arxiu Històric de Tarragona & 500.000 & 152.000 & 14.000 \\
\hline $\begin{array}{l}\text { Institut Cartogràfic de Cata- } \\
\text { lunya }\end{array}$ & 400.000 & 237.000 & 13.000 \\
\hline Arxiu Fotogràfic del CEC & 400.000 & 30.000 & 0 \\
\hline Arxiu Mas - Institut Amatller & 350.000 & 15.000 & 0 \\
\hline $\begin{array}{l}\text { Arxiu Fotogràfic del F. C. } \\
\text { Barcelona }\end{array}$ & 300.000 & 38.000 & 0 \\
\hline $\begin{array}{l}\text { Unitat Gràfica Biblioteca de } \\
\text { Catalunya }\end{array}$ & 200.000 & 40.000 & 10.000 \\
\hline SPAL Diputació de Barcelona & 200.000 & 8.000 & 0 \\
\hline MAE Institut del Teatre & 200.000 & 40.000 & 60 \\
\hline Arxiu Comarcal de l'Alt Penedès & 120.000 & 96.000 & 7.000 \\
\hline Arxiu d'Imatges d'Olot & 100.000 & 40.000 & 0 \\
\hline Museu Marítim de Barcelona & 90.000 & 45.000 & 10.000 \\
\hline $\begin{array}{l}\text { Arxiu Comarcal del Pallars } \\
\text { Sobirà }\end{array}$ & 76.000 & 11.000 & 6.000 \\
\hline Arxiu Històric de Girona & 66.000 & 2.400 & 900 \\
\hline Arxiu Comarcal de la Cerdanya & 61.000 & 57.000 & 2.400 \\
\hline $\begin{array}{l}\text { Arxiu Històric Diputació de } \\
\text { Barcelona }\end{array}$ & 60.000 & 20.000 & 0 \\
\hline $\begin{array}{l}\text { Arxiu Comarcal de l'Alt } \\
\text { Empordà }\end{array}$ & 30.000 & 30.000 & 2.100 \\
\hline $\begin{array}{l}\text { Fototeca del Temple Sagrada } \\
\text { Família }\end{array}$ & 8.000 & 8.000 & 0 \\
\hline
\end{tabular}

Tabla 1. Entidades citadas: patrimonio fotográfico, fondos digitalizados y 


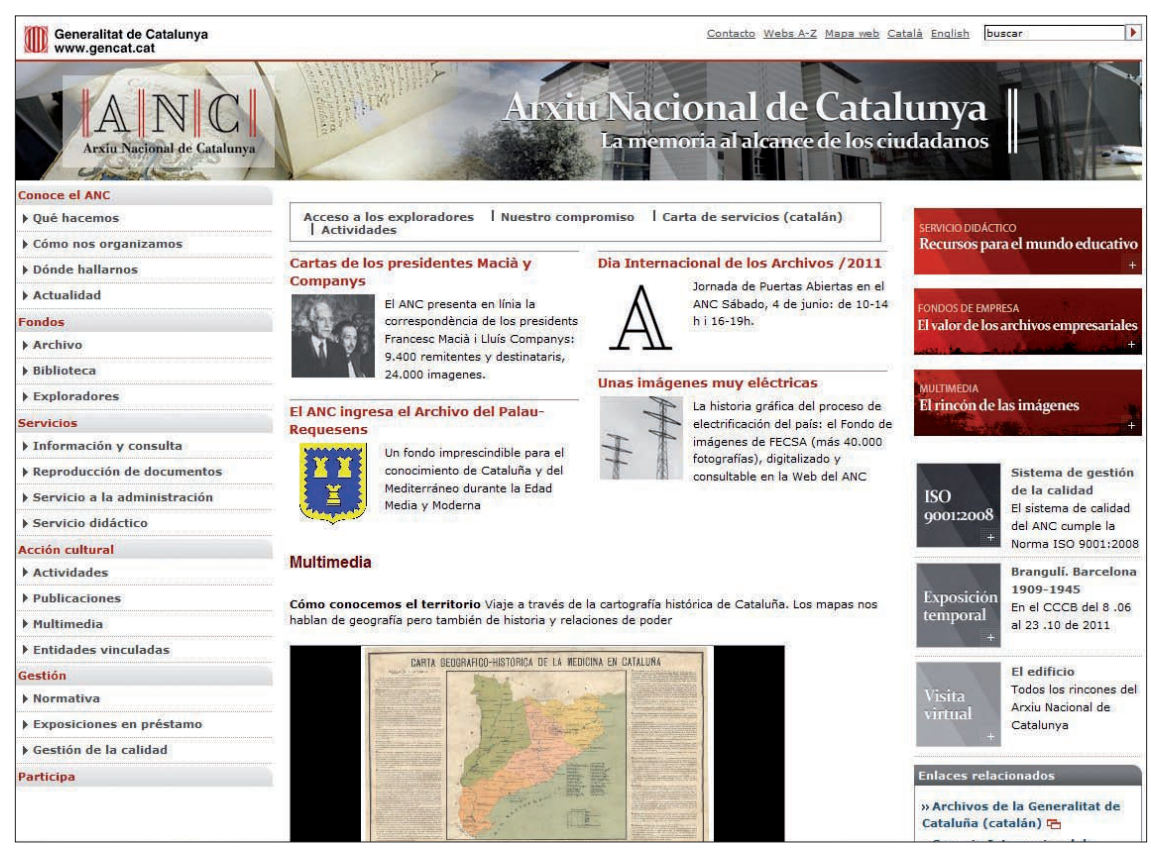

El Arxiu Nacional de Catalunya es líder en su comunidad autónoma en fotografías disponibles online (118.000 en mayo de 2011). http://anc.gencat.cat

del Teatre), Sílvia Dahl (Museu Marítim Barcelona), David González (Arxiu Històric de Sabadell), Sònia Granel (Inspai, Girona), Montserrat Hosta (Arxiu Històric de Girona), Ricard Ibarra (Arxiu Històric de Tarragona), David Iglesias (CRDI, Girona), Marta Llobera (Institut d'Estudis Ilerdencs), Ricard Marco (Biblioteca de Catalunya), Carme Maria Marrugan (Arxiu Comarcal del Pallars Sobirà), Josep M. Masachs (Arxiu Comarcal de l'Alt Penedés), Núria Miró (Arxiu Històric de la Diputació de Barcelona), Imma Navarro (Arxiu Nacional de Catalunya), Dolors Nieto (Arxiu Històric de Badalona), Joaquim Nolla (SADM, Tarragona), Núria Peiris (Arxiu Mas, Barcelona), Noèlia Ramos (Institut Cartogràfic de Catalunya), Marcel Russiñol (F. C. Barcelona), Jordi Serchs (Arxiu Fotogràfic de Barcelona), Erika Serna (Arxiu Comarcal de l'Alt Empordà), Erola Simon (Arxiu Comarcal de la Cerdanya), Laia Vinaixa (Arxiu Temple Sagrada Família).

Museos, archivos y bibliotecas tienen diferentes modelos descriptivos de los fondos fotográficos

También han sido significativas las contribuciones de Enric Cobo (Servei de Coordinació General d'Arxius de la Generalitat de Catalunya), Pere Pastallé (Oficina de Patrimoni Cultural de la Diputació de Barcelona) y Lluïsa Pla (Diputació de Lleida).

\section{Notas}

1. Museus en línia es un proyecto del Departament de Cultura de la Generalitat de Catalunya, consultable en la Red desde el año 2008. Actualmente -febrero 2011- contiene imágenes procedentes de 45 museos, si bien participan 107 museos, que ya están trabajando para ofrecer sus datos.

http://museusenlinia.gencat.cat

2. Calaix es un proyecto que da acceso a la documentación técnica de la Direcció General del Patrimoni Cultural como, por ejemplo, memorias de excavación arqueológica, planos y fotografías de restauraciones y monumentos. Se informa de su presentación en septiembre del 2010, en la web de esa Dirección General, si bien actualmente -febrero 2011- todavía no está en funcionamiento para su consulta en internet. Las imágenes fotográficas que incluye son las que forman parte de esta documentación técnica.

3. El buscador Arxius en línia ha sido creado por el Departament de Cultura i Mitjans de Comunicació (DCMC) de la Generalitat de Catalunya, y presenta imágenes de documentos conservados en sus propios archivos. http://cultura.gencat.cat/ArxiusEnLinia

4. Eureca es un buscador de internet promovido por el $D C M C$ que permite acceder a la información contenida en los depósitos o colecciones digitales de Catalunya.

http://eureca.cultura.gencat.cat

\section{Bibliografía}

Blanch, Albert (coord.). Arxius fotogràfics de Catalunya. Inventari d'arxius fotogràfics públics i privats de Catalunya. Barcelona: Azimut, 1998.

http://www.ultrafox.com/sp/default.htm

Boadas, Joan. El patrimoni fotogràfic documental a Catalunya: balanç i propostes, 2009.

http://www.tv3.cat/multimedia/pdf/5/1/1279114884315. $p d f$

Estadística d'arxius. 1998-2004: Estadístiques culturals de Catalunya. Barcelona: Generalitat de Catalunya, Departament de Cultura i Mitjans de Comunicació, 2007.

http://www20.gencat.cat/docs/CulturaDepartament/Cultu ra/Documents/Arxiu/Arxius\%20GT/Estadistica_arxius_Cat 1998_2004.pdf

Vicente-Guitart, Carles. "Els arxius d'imatges a Catalunya: balanç i perspectives". En: Jornades La imatge i la recerca històrica, pp. 7-21. Girona: Ajuntament, 1990.

http://www.girona.cat/sgdap/docs/quuyyq/carles\%20vicen te\%20i\%20guitart.pdf

Zelich, Cristina. (coord.). Llibre blanc del patrimoni fotogràfic a Catalunya. Barcelona: Generalitat de Catalunya. Departament de Cultura, 1996. ISBN: 8439339844 